\title{
Involvement of calcitonin gene-related peptide in migraine: regional cerebral blood flow and blood flow velocity in migraine patients
}

\author{
L. H. Lassen - V. B. Jacobsen · P. A. Haderslev • \\ B. Sperling $\cdot$ H. K. Iversen $\cdot$ J. Olesen $\cdot$ P. Tfelt-Hansen
}

Received: 4 March 2008/Accepted: 31 March 2008/Published online: 25 April 2008

(C) Springer-Verlag 2008

\begin{abstract}
Calcitonin gene-related peptide (CGRP)-containing nerves are closely associated with cranial blood vessels. CGRP is the most potent vasodilator known in isolated cerebral blood vessels. CGRP can induce migraine attacks, and two selective CGRP receptor antagonists are effective in the treatment of migraine attacks. It is therefore important to investigate its mechanism of action in patients with migraine. We here investigate the effects of intravenous human alpha-CGRP (h $\alpha \mathrm{CGRP}$ ) on intracranial hemodynamics. In a double-blind, cross-over study, the effect of intravenous infusion of h $\alpha$ CGRP $(2 \mu \mathrm{g} / \mathrm{min})$ or placebo for $20 \mathrm{~min}$ was studied in 12 patients with migraine without aura outside attacks. Xenon-133 inhalation SPECT-determined regional cerebral blood flow (rCBF) and transcranial Doppler (TCD)-determined blood velocity $\left(V_{\text {mean }}\right)$ in the middle cerebral artery (MCA), as well as the heart rate and blood pressure, were the outcome parameters. No change of $\mathrm{rCBF}$ was observed at the end of infusion $[1.2 \% \pm 1.7$ with $\mathrm{h} \alpha \mathrm{CGRP}$, vs. $-1.6 \% \pm 3.1$ with placebo (mean $\pm \mathrm{SD})](P=0.43) . V_{\text {mean }}$ in MCA decreased to $13.5 \% \pm 3.6$ with $\mathrm{h} \alpha \mathrm{CGRP}$ versus $0.6 \% \pm 1.8$ with placebo $(P<0.005)$. Since rCBF was unchanged, this indicates a dilation of the MCA. h $\alpha$ CGRP induced a decrease in MAP $(12 \%)(P<0.005)$ and an increase in heart rate $(58 \%)(P<0.0001)$. CGRP dilates
\end{abstract}

L. H. Lassen - V. B. Jacobsen - P. A. Haderslev .

H. K. Iversen · J. Olesen · P. Tfelt-Hansen ( $\square)$

Department of Neurology, Glostrup Hospital,

University of Copenhagen, 2600 Glostrup, Denmark

e-mail: ptha@glo.regionh.dk

B. Sperling

Department of Clinical Physiology and Nuclear Medicine,

Bispebjerg Hospital, Copenhagen, Denmark cerebral arteries, but the effect is so small that it is unlikely to be the only mechanism of CGRP-induced migraine.

Keywords Human calcitonin gene-related peptide . Cerebral arteries - Transcranial Doppler .

Regional cerebral blood flow $\cdot$ Migraine

\section{Introduction}

Based on animal research showing calcitonin gene-related peptide (CGRP) in perivascular nerves [1] and a strong vasodilator effect of CGRP on cerebral blood vessels [2], a role for CGRP in the pathogenesis of migraine pain was first suggested by reports of increased CGRP in external jugular venous blood during migraine attacks [3-5]. In one recent study, there was, however, no increase of CGRP [6]. More solid evidence was presented in a study which demonstrated that, CGRP infused intravenously in patients with migraine was able to induce a vascular type headache in great majority of patients and in some patients this headache fulfilled all diagnostic criteria for migraine without aura [7]. The final proof of the involvement of CGRP in migraine mechanisms was provided by two phase II clinical trials [8,9], demonstrating significant efficacy of the specific CGRP antagonists, BIBN4096BS [10] and MK0974 [9]. Thus, CGRP is not only able to induce attacks, but it seems to be continuously important throughout the entire migraine attack. CGRP is one of the most potent dilators of isolated cerebral arteries known today [2, 11], but possible species differences make it difficult to predict the effect of CGRP in the human cerebral circulation. Although the effect of CGRP on the cerebral circulation has been studied in normal subjects [12], it is important to study it also in patients with 
migraine in whom migraine-like headache and migraine attacks are induced by CGRP [7]. The aim of the present study was therefore to investigate the cerebral hemodynamic effects of CGRP in patients with migraine outside of attack.

\section{Patients and methods}

\section{Patients}

Twelve patients with migraine (11 females, 1 male; mean age 39.5 years, range 31-47 years; mean weight $69.7 \mathrm{~kg}$, range $51-89 \mathrm{~kg}$ ) were included. All suffered from migraine without aura according to criteria of the International Headache Society [13]. The subjects were not allowed to take medication, coffee, tea, alcohol or tobacco for $12 \mathrm{~h}$ before the study, and they were not allowed to take a triptan $24 \mathrm{~h}$ or ergotamine $48 \mathrm{~h}$ before the study.

Exclusion criteria were as follows: use of any kind of daily medication including prophylactic headache therapy but excluding oral contraceptives; pregnancy or breastfeeding; excessive use of analgesics or alcohol; serious somatic or psychiatric disorders; ischaemic heart disease; a supine systemic blood pressure more than 160/90 or less than $110 / 75 \mathrm{mmHg}$ at entry of study.

Patients were informed that they were free to withdraw at any time and all gave written informed consent. The study was approved by the local ethics committees of Copenhagen and Copenhagen County (KA 96054) and complied with the Declaration of Helsinki.

\section{Design and procedure}

The patients with migraine were studied outside of attacks. The study used a double-blind, placebo-controlled crossover design. Subjects were randomized to receive $2 \mu \mathrm{g} / \mathrm{min}$ human $\alpha$ CGRP (h $\alpha$ CGRP; Clinalfa, Switzerland) or placebo $(0.9 \% \mathrm{NaCl})$ infused intravenously for $20 \mathrm{~min}$ on 2 days separated by at least 1 week. The dose was chosen as the highest tolerated dose (because of blood pressure reduction) based on reports in the literature [14, 15]. Patients were randomly assigned by computer (Med. Stat ${ }^{\circledR}$, version 2.12 ). Randomization and preparation of study drugs was done by medical staff, who were not involved in the study. Five patients started with placebo and seven with h $\alpha$ CGRP. This quota was chosen by the computer and not known before the study. The effectiveness of blinding was not estimated.

When subjects arrived at the laboratory, a cannula (Viggo Venflon ${ }^{\circledR}, 1.4 \mathrm{~mm}$ ) was placed in the right cubital vein for $h \alpha C G R P / p l a c e b o$ infusion. Baseline values of mean maximal blood velocity (Vmean) in the middle cerebral artery (MCA), regional cerebral blood flow ( $\mathrm{rCBF}$ ), blood pressure, heart rate and $\mathrm{pCO}_{2}$ were recorded after $30 \mathrm{~min}$ of rest in the supine position in a quiet room. Then, h $\alpha$ CGRP or placebo was infused intravenously for 20 min by a volumetric pump (Braun Perfuser). Vmean, blood pressure, heart rate and end tidal $\mathrm{pCO}_{2}$ were recorded every $10 \mathrm{~min}$ during and after infusion until $80 \mathrm{~min}$ after start of the h $\alpha$ CGRP infusion. $\mathrm{rCBF}$ was measured again during the last $5 \mathrm{~min}$ of infusion and at 75-80 $\mathrm{min}$ after start of $\mathrm{h} \alpha \mathrm{CGRP} /$ placebo infusion. At every recording, it was noticed if volunteers were flushing and information about headache presence, intensity (measured on a $0-10$ scale) and characteristics were obtained before, during and after the infusions. The results concerning headache response have been published elsewhere [7].

Methods

rCBF was measured with a highly sensitive, brain-dedicated, fast-rotating, single photon emission computerized tomograph (Tomomatic 232). Each study lasted $4.5 \mathrm{~min}$. A mixture of atmospheric air and ${ }^{133}$ Xenon was rebreathed during the first $1.5 \mathrm{~min}$ through a closed system from a 4-L reservoir (740 Mbq/L). During the last $3 \mathrm{~min}$, the ${ }^{133}$ Xenon mixture was expired against atmospheric air. $\mathrm{rCBF}$ was recorded simultaneously in two slices positioned 50 and $90 \mathrm{~mm}$ above and parallel to the orbito-meatal plane (OM). Each slice was $16 \mathrm{~mm}$ thick and the distance between the centers of slices was $40 \mathrm{~mm}$. The full width half maximum resolution of the instrument is about $16 \mathrm{~mm}$ in the horizontal plane. rCBF was calculated according to Celsis et al. [16].

A fixed matrix of regions of interest was superimposed on the rCBF picture. The shape and size were fitted to the outlines on the brain excluding extracranial flow. Regional mean values were calculated within the predefined regions of interest. The matrix was divided into regions of interest representing the hemispheric $\mathrm{rCBF}$ regions and the vascular territories of supply by the anterior-, middle- and posterior cerebral arteries. The maximum whole body radiation was approximately $0.6 \mathrm{mSV}$ per rCBF measurement [17].

Time averaged mean of the maximal blood velocity $\left(V_{\text {mean }}\right)$ in MCA at the usual headache side was measured with transcranial Doppler (TCD) ultrasonography (2 MHz, Multidop X Doppler: DWL, Sipplingen, Germany). A mean of four consecutive values of $V_{\text {mean }}$ was taken (each representing the mean value of typically four to five heart beats automatically calculated by the computer). Positions of the measurements were reproduced from day to day by recording the position in relation to the angle and distance relative to the orbito-meatal line. Blood pressure and heart rate were measured with an automatic inflatable arm cuff 
(Omega 1400, Invivo Research Laboratory, New York, USA). Simultaneously, with each $\mathrm{rCBF}$ and TCD measurement, the end expiratory $\mathrm{pCO}_{2}$ was recorded by means of a capnograph (Datex OY, CD 101).

\section{Statistics}

Hemodynamic responses are given as mean and standard deviation $( \pm \mathrm{SD})$. Differences in blood velocity, $\mathrm{rCBF}$, blood pressure, heart rate and $\mathrm{pCO}_{2}$ over time within the group were analyzed with analysis of variance (MANOVA, Statgraphics ${ }^{\circledR} 7.0$ ), and changes were then located with a multiple range test (Confidence intervals, Statgraphics ${ }^{\circledR}$ 7.0).

Differences in the delta values (baseline-the last measurement during infusion and baseline-the last measurement during the study) in $V_{\text {mean }}, \mathrm{rCBF}$, blood pressure, heart rate and $\mathrm{pCO}_{2}$ between the effect of $\mathrm{h} \alpha \mathrm{CGRP}$ and the effect of placebo were tested with a paired $t$ test (Statgraphics $\left.{ }^{\circledR} 7.0\right)$. In all tests, $P<0.05$ was considered statistically significant.

\section{Results}

During CGRP infusion, two volunteers experienced a substantial decrease in blood pressure (70/50 and 65/25, respectively) causing the infusion to be terminated ahead of time. Signs and symptoms were pallor, cold sweat, stomach ache, nausea and palpitation. The situation was restored after placing the volunteers in head-down tilt for 7 and 20 min, respectively. No rCBF and TCD measurements were taken during this time period, and therefore, results from these two volunteers were excluded from the calculations below.

Changes in end tidal $\mathrm{pCO}_{2}$

End-tidal $\mathrm{pCO}_{2}$ decreased significantly over time when volunteers were treated with h $\alpha \mathrm{CGRP}(P<0.0001)$ but not when treated with placebo $(P<0.26$, MANOVA). The $\mathrm{pCO}_{2}$ decrease at the last measurement during infusion was $-4.0 \% \pm 0.8 \%$ when treated with $\mathrm{h} \alpha \mathrm{GCRP}$ versus $0.7 \% \pm 1.0 \%$ when treated with placebo $(P<0.05$, paired $t$ test). The peak decrease in end-tidal $\mathrm{pCO}_{2}$ induced by $\mathrm{h} \alpha \mathrm{CGRP}(-6.8 \% \pm 2.6 \%)$ occurred at $25 \mathrm{~min}, 5 \mathrm{~min}$ after end of infusion.

\section{Transcranial Doppler measurements}

The TCD examination was performed on the side of usual migraine. The following data for $V_{\text {mean }}$ in MCA are corrected for changes in $\mathrm{pCO}_{2}$ according to Markwalder et al. [18]:
$V_{\text {mean }(\text { korr })}=V_{\text {mean (meas) }} \exp \left(0.04\left(\mathrm{pCO}_{2(\text { Basal })}-\mathrm{pCO}_{2(n)}\right)\right)$

$V_{\text {mean }}$ changed significantly over time when patients were treated with h $\alpha$ CGRP $(P<0.0001$, MANOVA), but not when treated with placebo $(P=0.26$, MANOVA). At the last measurement during infusion, 15 min after its beginning, $V_{\text {mean }}$ compared to baseline was $-13.5 \% \pm$ 11.4 when treated with hCGRP, versus $0.6 \% \pm 5.6$ when treated with placebo $(P<0.005$, paired $t$ test). At the end of the in-hospital period (75 min after start of the infusion), there was no difference between the two groups $(P=0.97$, paired $t$ test) (Fig. 1, Table 1). There was a positive correlation between $\Delta V_{\text {mean }}$ and $\Delta \mathrm{MABP}(r=0.703$, $P<0.05)$.

Regional cerebral blood flow

All data have been corrected for changes in $\mathrm{pCO}_{2}$ : $\mathrm{rCBF}_{(\text {korr })}=\mathrm{rCBF}_{\text {(meas) }} \times \exp \left(0.04\left(\mathrm{pCO}_{2 \text { (Basal) }}-\mathrm{pCO}_{2(n)}\right)\right.$. For comparison of $V_{\text {mean }}$ and $\mathrm{rCBF}$, we calculated $\mathrm{rCBF}$ in the territory of MCA, the artery used for TCD examination. Area-weighted data from the $\mathrm{OM}+50 \mathrm{~mm}$ and $\mathrm{OM}+90 \mathrm{~mm}$ were used for the results given below.

There was no change over time neither when patients were treated with h $\alpha \mathrm{CGRP}(P=0.26)$ nor when they were treated with placebo $(P=0.88$, MANOVA $)$. During infusion, $\mathrm{rCBF}$ compared to baseline was $+1.2 \% \pm 5.5$ when treated with $\mathrm{h} \alpha \mathrm{CGRP}$ versus $-1.6 \% \pm 9.8$ when treated with placebo. The difference between CGRP and placebo was not significant $(P=0.43$, paired $t$ test). Furthermore, no significant difference between CGRP and

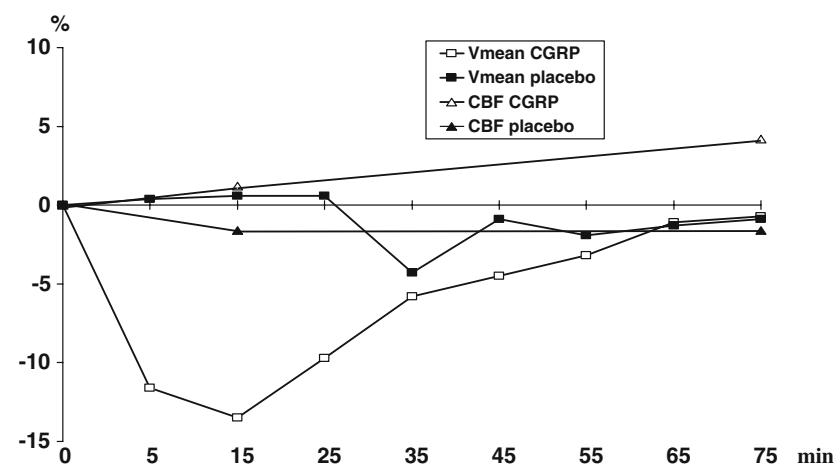

Fig. 1 The effect of hCGRP $(2 \mu \mathrm{g} / \mathrm{min})$ for $20 \mathrm{~min}$ and the effect of placebo on the mean velocity $\left(V_{\text {mean }}\right)$ in middle cerebral artery (squares) and the regional cerebral blood flow ( $\mathrm{rCBF}$ ) (triangles) in the territory of the middle cerebral artery (MCA) used for transcranial Doppler examination. $X$-axis: time from start of infusion (min), $y$-axis: changes in percent of baseline. $V_{\text {mean }}$ (squares) decreased $-13.5 \% \pm 3.6$ compared to baseline with hCGRP treatment versus $0.6 \% \pm 1.8$ with placebo treatment $(P<0.0001)$. After $75 \mathrm{~min}$, there was no difference between the two groups $(P=0.97)$. No change of rCBF (triangles) was observed at the end of infusion $(P=0.43)$ or at the end of study period $(P=0.12)$ 
Table 1 The maximum mean blood velocity $\left(V_{\text {mean }}\right)$ in the middle cerebral artery (MCA)

\begin{tabular}{|c|c|c|c|c|c|c|}
\hline \multirow[t]{3}{*}{ Time $(\min )$} & \multicolumn{6}{|c|}{$V_{\text {mean }}$ in $\mathrm{MCA}(\mathrm{cm} / \mathrm{s})$} \\
\hline & \multicolumn{2}{|c|}{ No $\mathrm{pCO}_{2}$ correction } & \multicolumn{4}{|c|}{ Corrected for $\mathrm{pCO}_{2}$ changes } \\
\hline & CGRP & Placebo & CGRP & Placebo & CGRP\% & Placebo $\%$ \\
\hline 0 & $81.6(10.7)$ & $79.9(12.3)$ & $81.6(10.7)$ & $79.9(12.3)$ & 0 & 0 \\
\hline $15-20$ & $66.9(13.5)^{*}$ & $79.5(12.4)$ & $70.7(14.2)^{*}$ & $80.3(12.7)$ & $-13.5(11.4)^{*}$ & $0.6(5.6)$ \\
\hline $75-80$ & $76.6(9.9)$ & $77.4(12.7)$ & $80.6(11.3)$ & $79.2(13.6)$ & $-0.7(11.6)$ & $-0.9(6.4)$ \\
\hline
\end{tabular}

Values within parentheses represent the standard deviation (SD)

Data is shown with and without $\mathrm{pCO}_{2}$ correction according to Markwalder et al. [18]

The $\mathrm{pCO}_{2}$-corrected data is shown as absolute data and in percent change from baseline $(P<0.001)$

* Significant changes compared with baseline

placebo was found at the end of the study period $(P=0.12$, paired $t$ test) (Fig. 1, Table 2).

The absolute rCBF data and the $\mathrm{rCBF}$ data with $\mathrm{pCO}_{2}$ correction concerning the MCA area relevant for TCD examination are given in Table 2. There was also no significant difference in $\mathrm{pCO}_{2}$-uncorrected $\mathrm{rCBF}$ between CGRP and placebo during $(P=0.78$, paired $t$ test $)$ or after the infusion $(P=0.357$, paired $t$ test). There was a negative correlation between $\triangle \mathrm{rCBF}_{(\mathrm{MCA})}$ and $\triangle \mathrm{MABP}(r=$ $-0.654, P<0.05)$. rCBF during h $\alpha$ CGRP infusion was not significantly different in any territory or at any time point.

\section{Blood pressure}

The mean arterial blood pressure (MABP) decreased significantly over time when patients were treated with $\mathrm{h} \alpha \mathrm{CGRP}(P<0.0001)$, but not when they were treated with placebo $(P=0.48$, MANOVA $)$. The maximal decrease occurred at the last measurement during infusion (20 min after start of infusion) and amounted to $-12.3 \% \pm$ $8.1 \%$ with $\mathrm{h} \alpha \mathrm{CGRP}$ treatment versus $+2.4 \% \pm 5.9 \%$ with placebo treatment $(P<0.005$, paired $t$ test). MABP had normalized at the end of the study period $(80 \mathrm{~min}$ from start of infusion) $(P=0.49)$ (Table 3$)$. Both systolic and diastolic blood pressures decreased during infusion of CGRP compared to that during infusion of placebo $(P<0.05)$.

\section{Heart rate}

When patients were treated with $\mathrm{h} \alpha \mathrm{CGRP}$, heart rate increased significantly over time $(P<0.0001$, MANOVA), but not when they were treated with placebo $(P=0.44$, MANOVA). The peak increase in heart rate after h $\alpha$ CGRP treatment occurred $20 \mathrm{~min}$ after start of infusion reaching $58.1 \% \pm 22.7 \%$ versus $1.9 \% \pm 5.58 \%$ with placebo treatment $(P<0.0001$, paired $t$ test $)$. Heart rate after h $\alpha$ CGRP treatment was still different from that after placebo treatment at the end of the study period $(P<0.005$, paired $t$ test) (Table 3).

\section{Other signs}

Flushing after h $\alpha$ CGRP treatment was pronounced and appeared only in the face, neck and upper chest. It appeared from 10 min (time of first observation) after start of the

Table 2 Regional cerebral blood flow $\mathrm{rCBF}$ in the MCA territory recorded 50 and $90 \mathrm{~mm}$ above the orbitomeatal plane (OM)

\begin{tabular}{|c|c|c|c|c|c|c|}
\hline \multicolumn{7}{|c|}{ Cerebral blood flow (ml blood $/ 100 \mathrm{~g} / \mathrm{min}$ ) } \\
\hline \multirow[t]{4}{*}{ Time (min) } & \multicolumn{6}{|c|}{ MCA $(\mathrm{OM} 50+\mathrm{OM} 90)$ in the territory used for TCD examination } \\
\hline & \multicolumn{2}{|c|}{ No $\mathrm{pCO}_{2}$ correction } & \multicolumn{4}{|c|}{ Corrected for $\mathrm{pCO}_{2}$ changes } \\
\hline & \multicolumn{2}{|c|}{ Absolute data } & \multicolumn{2}{|c|}{ Absolute data } & \multicolumn{2}{|c|}{ Data in $\%$ of baseline } \\
\hline & CGRP & Placebo & CGRP & Placebo & CGRP & Placebo \\
\hline 0 & $70.8(13.7)$ & $67.7(9.3)$ & $70.8(13.7)$ & $67.7(9.3)$ & 0 & 0 \\
\hline $15-20$ & $66.8(9.4)$ & $65.3(11.6)$ & $71.1(10.5)$ & $66.7(11.4)$ & $1.2(1.7)$ & $-1.6(3.1)$ \\
\hline $75-80$ & $69.3(7.9)$ & $65.0(9.8)$ & $72.8(8.7)$ & $66.7(10.4)$ & $4.2(3.0)$ & $-1.6(2.8)$ \\
\hline
\end{tabular}

Values within parentheses represent the standard deviation (SD)

Data is shown with and without $\mathrm{pCO}_{2}$ correction according to Markwalder et al. [18]

The $\mathrm{pCO}_{2}$-corrected data is shown as absolute data and in percent change from baseline $(P<0.001)$ 
Table 3 The mean arterial blood pressure (MABP), systolic and diastolic blood pressure ( $\mathrm{mmHg}$ ) and heart rate (bpm) after CGRP and placebo treatment

\begin{tabular}{|c|c|c|c|c|c|c|c|c|}
\hline \multicolumn{7}{|c|}{ Blood pressure $(\mathrm{mmHg})$} & \multicolumn{2}{|c|}{ Heart rate (bpm) } \\
\hline \multirow[t]{2}{*}{ Time (min) } & \multicolumn{2}{|l|}{ MABP } & \multicolumn{2}{|l|}{ Systolic BP } & \multicolumn{2}{|c|}{ Diastolic BP } & \multirow[b]{2}{*}{ CGRP } & \multirow[b]{2}{*}{ Placebo } \\
\hline & CGRP & Placebo & CGRP & Placebo & CGRP & Placebo & & \\
\hline 0 & $87.8(9.6)$ & $91.6(9.5)$ & $117.0(11.1)$ & $119.0(12.6)$ & $73.2(9.5)$ & $77.9(9.4)$ & $63.0(6.0)$ & $64.4(7.2)$ \\
\hline 15 & $78.0(7.5)^{*}$ & $90.0(9.2)$ & $110.7(9.6)$ & $117.2(12.5)$ & $61.7(7.8)$ & $76.4(8.7)$ & $92.9(10.2)^{*}$ & $63.8(6.8)$ \\
\hline 20 & $76.9(10.1)^{*}$ & $93.5(8.3)$ & $112.2(13.3)$ & $123.9(11.6)$ & $59.3(9.1)$ & $78.3(7.6)$ & $98.9(11.2)^{*}$ & $65.5(7.1)$ \\
\hline 75 & $86.5(9.2)$ & $91.4(8.7)$ & $117.6(12.0)$ & $121.9(13.4)$ & $71.0(8.9)$ & $76.2(7.2)$ & $76.1(7.0)^{*}$ & $62.9(6.0)$ \\
\hline 80 & $85.3(9.2)$ & $91.3(9.9)$ & $116.4(13.2)$ & $123.3(11.3)$ & 69.7 (8.4) & $75.3(9.7)$ & $75.3(7.7)^{*}$ & $64.4(5.3)$ \\
\hline
\end{tabular}

Values within parentheses represent \pm standard deviation $( \pm \mathrm{SD})$

$* P<0.05$

infusion of haCGRP in all patients until median $70 \mathrm{~min}$ after start of infusion (range 20-80 min). There was no flushing when the patients were treated with placebo. The median headache during infusion of h $\alpha \mathrm{CGRP}$ was 1 versus 0 in the placebo-treated group $(P<0.01)$. During the following $11 \mathrm{~h}$, all patients experienced headache after $\mathrm{h} \alpha \mathrm{CGRP}$ treatment versus the one after placebo treatment $(P<0.001)$. The median headache score was 4 after h $\alpha$ CGRP treatment and 0 after placebo treatment. For details, see [7].

\section{Discussion}

The main finding of the present study was that CGRPinfusion dilated the MCA in patients with migraine, while cerebral blood flow remained unchanged. The dose of $2 \mu \mathrm{g} / \mathrm{min}$ of CGRP was chosen from the literature in which the same dose of $545 \mathrm{pmol} / \mathrm{min}$ was given in healthy volunteers without any reported adverse events [14]. In another study, up to $25 \mu \mathrm{g}$ CGRP was given as an intravenous bolus injection and all subjects had facial flushing [15]. The dose of $2 \mu \mathrm{g} / \mathrm{min}$ for $20 \mathrm{~min}$ is probably the maximally tolerated dose of CGRP in patients with migraine, since it resulted in a substantial decrease of MABP and a marked increase in heart rate. Two subjects were near fainting and had to be withdrawn. In healthy volunteers, a dose of $1.5 \mu \mathrm{g} / \mathrm{min}$ was used without adverse events apart from flushing and without any effect on mean blood pressure [12]. It remains uncertain whether the stronger circulatory response in the present study was exclusively due to the higher dose or whether patients with migraine are more sensitive to CGRP. After $20 \mathrm{~min}$ infusion at $1.5 \mu \mathrm{g} / \mathrm{min}$, the mean plasma level was $340 \mathrm{pmol} / \mathrm{L}$ in healthy volunteers [12]. It can be calculated from these results that the plasma level would be $450 \mathrm{pmol} / \mathrm{L}$ in our patients with migraine. The $\mathrm{EC}_{50}$ for CGRP for the dilatory effect on human pial arteries is $500 \mathrm{pmol} / \mathrm{L}$ [19]. The dose of CGRP used in the present study thus resulted in a plasma level very near to the $\mathrm{EC}_{50}$ for cerebral arteries in vitro.

The blinding of the present study can be criticized. Signs (increased heart rate) and symptoms (facial flushing and feeling of warmth) during CGRP infusion made it difficult to keep the study completely blinded. However, the present design is the best one available, because no technique is available to disguise such symptoms.

An interesting finding of the present study is the significant reduction of blood velocity ( $13.5 \%$ decrease) in the MCA, but $\mathrm{rCBF}$ remained unchanged during intravenous $h \alpha$ CGRP-infusion. A reduced velocity in an artery, with unchanged regional blood flow in its territory of supply, reflects dilation [20]. The relative diameter change can be roughly estimated from the relation: flow $=$ mean velocity multiplied by the cross-sectional area of the artery $\left(2 \pi r^{2}\right)$. When the flow is constant, velocity is a function of the reciprocal value of $r^{2}$ and $V_{\mathrm{a}} / V_{\mathrm{b}}=r_{\mathrm{b}}^{2} / r_{\mathrm{a}}^{2}$ [20]. We can thus estimate from the change in mean velocity that the $\mathrm{h} \alpha \mathrm{CGRP}$ infusion caused a $7.5 \%$ increase in MCA diameter corresponding to $17 \%$ increase of its cross sectional area.

$\alpha$ CGRP infused in a considerably lower dose $(0.6 \mu \mathrm{g} /$ min) did not change MCA velocity or rCBF in healthy volunteers [21], while the dose of $1.5 \mu \mathrm{g} / \mathrm{min}$ in volunteers dilated the MCA (9\% increase in diameter) to the same extent as in the present study [12]. The dilatation of MCA in the present study could, theoretically, be due to cerebrovascular autoregulation secondary to decreased blood pressure. However, conduction arteries like MCA do normally only autoregulate due to blood pressure changes to a much lesser extent than arterioles (for review, see [22]). A positive correlation $(r=0.7, P<0.05)$ between changes in MCA and changes in MABP seems to support this possibility. However, this correlation could also reflect that MCA and systemic circulation vary in parallel. In healthy volunteers, using a slightly lower CGRP dose of $1.5 \mu \mathrm{g} /$ min, blood pressure was unchanged but MCA dilated to the 
same extent as in the present study [12]. This strongly indicates that MCA dilation is a direct effect of CGRP.

In rat MCA, using the in vitro-pressurized arteriographic model, luminal CGRP was without any dilating effect, whereas abluminal CGRP dilated the artery [23]. This indicated that CGRP was unable to cross the blood-brain barrier in rat MCA. In contrast, both in patients with migraine (Fig. 1) and in healthy volunteers [12], a dilation of MCA was observed. Theoretically, CGRP could act on an endothelial receptor, but this is unlikely because the CGRP antagonist BIBN4096BS could not block the effect on MCA in man [12]. Furthermore, in man, the calcitonin receptor-like receptor (CLR) and receptor activity-modifying protein (RAMP) are located mainly in the muscular layer of the human MCA [24]. In the endothelium, there was only a minor amount of CLR and largely absent RAMP1 [24]. There is thus no CGRP receptor (CLR plus RAMP1) on the endothelium. The present results with a dilation of MCA could indicate that the blood-brain barrier to CGRP in the MCA is less tight in man than in rats, possibly related to the large difference in size.

In healthy volunteers, dilation of MCA was accompanied by a modest (14\%) increase in rCBF [12], whereas in the present study, in patients with migraine, a $5 \%$ increase in $\mathrm{rCBF}$ was not statistically significant (Fig. 1). The discrepancy may be due to random variation. Altered cerebrovascular reactivity in patients with migraine compared to controls is another possibility. The decrease of mean MABP from 88 to $77 \mathrm{mmHg}$ observed in the present study could also be a factor if autoregulation was disturbed by CGRP.

In patients with subarachnoid hemorrhage, a CGRPinfusion concomitant with intravenous fluid to correct any drop in blood pressure resulted in a dilation of the MCA on the vasospasm side [25]. Blood pressure was unchanged while heart rate and cardiac output were increased and total peripheral resistance was decreased [25]. In two studies in man [14, 15], an increase in noradrenaline in plasma was observed after CGRP. We found in the present study a decrease in mean blood pressure and an increase in heart rate as would be expected after administration of a potent vasodilator such as CGRP.

In conclusion, the potent endogenous migraine-inducing molecule CGRP resulted in a dilation of MCA and unchanged rCBF. CGRP can thus most likely cross the blood-brain barrier to some extent in the large human cerebral arteries. The vasodilator effect on these arteries is in our opinion, however, so small that it is unlikely to be the only mechanism of CGRP-induced migraine observed in our patients with migraine [7].

Acknowledgments We thank Mrs. Bente Dall and Mrs. Eva Broedsgaard for technical assistance. This study was supported by the Lundbeck Foundation via the Lundbeck Foundation Center for Neurovascular Signaling (LUCENS).

Conflicts of interest None of the authors have any conflict of interest in connection with this work.

\section{References}

1. Edvinsson L, Fredholm BB, Hamel E, Jansen I, Verrechia C (1985) Perivascular peptides relax cerebral arteries concomitant with stimulation of cyclic adenosine monophosphate accumulation or release of an endothelium-derived relaxing factor in the cat. Neurosci Lett 58:213-217

2. McCulloch J, Udmann R, Kingman TA, Edvinsson L (1986) Calcitonin gene-related peptide: functional role in cerebrovascular regulation. Proc Natl Acad Sci USA 83:5731-5735

3. Edvinsson L (2004) Blockade of CGRP of receptors in the intracranial vasculature: a new target in the treatment of headache. Cephalalgia 24:611-612

4. Goadsby PJ, Edvinsson L, Ekman R (1990) Vasoactive peptide release in the extracerebral circulation of humans during migraine attacks. Ann Neurol 28:183-187

5. Goadsby PJ, Edvinsson L (1993) The trigeminovascular system and migraine: studies characterizing cerebrovascular and neuropeptide changes seen in humans and cats. Ann Neurol 33:48-56

6. Tvedskov JF, Lipka K, Ashina M, Iversen HK, Schifter S, Olesen $\mathrm{J}$ (2005) No increase of calcitonin gene-related peptide in jugular blood during migraine. Ann Neurol 58:561-563

7. Lassen LH, Haderslev PA, Jacobsen VB, Iversen HK, Sperling B, Olesen J (2002) CGRP may play a causative role in migraine. Cephalalgia 22:54-61

8. Olesen J, Diener H-C, Husstedt IW, Goadsby PJ, Hall D, Meier U, Pollentier S, Lesko LM (2004) BIBN 4096 BS Clinical Proof of Concept Study Group. Calcitonin gene-related peptide receptor antagonist BIBN 4096 BS for the acute treatment of migraine. N Engl J Med 350:1104-1110

9. Ho TW, Mannix LK, Fan X, Assaid C, Furtek C, Jones CJ, Lines CR, Rapoport AM; On behalf of the MK-0974 Protocol 004 Study Group (2007) Randomized controlled trial of an oral CGRP antagonist, MK-0974, in acute treatment of migraine. Neurology [Epub ahead of print]

10. Doods H, Hallermayer G, Wu D, Entzeroth M, Rudolf K, Engel W, Eberlein W (2000) Pharmacological profile of BIBN4096BS, the first selective small molecule CGRP antagonist. $\mathrm{Br} \mathrm{J}$ Pharmacol 129:420-423

11. Edvinsson L, Ekman R, Jansen I, Ottosson A, Uddman R (1987) Peptide-containing nerve fibers in humuman cerebral arteries: immonucytochemistry, radioimmunoassay, and in vitro pharmacology. Ann Neurol 21:431-437

12. Petersen KA, Lassen LH, Birk S, Lesko L, Olesen J (2005) BIBN4096BS antagonizes human $\alpha$-calcitonin gene related peptide-induced headache and extracerebral artery dilatation. Clin Pharmacol Ther 77:202-213

13. Headache Classification Committee of the International Headache Society (1988) Classification and diagnostic criteria for headache disorders, cranial neuralgias and facial pain. Cephalalgia 8:1-96

14. Struthers AD, Brown MJ, MacDonald DW, Beacham JL, Stevenson JC, Morris HR, MacIntyre I (1986) Human calcitonin gene related peptide: a potent endogenous vasodilator in man. Clin Sci (Lond) 70:389-393

15. Howden CW, Logue C, Gavin K, Collie L, Rubin PC (1988) Haemodynamic effects of intravenous human calcitonin-generelated peptide in man. Clin Sci (Lond) 74:413-418 
16. Celsis P, Goldman T, Henriksen L, Lassen NA (1981) A method for calculating regional cerebral blood flow from emission computed tomography of inert gas concentrations. J Comput Assist Tomogr 5:641-645

17. Holm S, Friberg L, Iversen HK, Lassen NA (1990) Dual energy brain SPECT-methods and applications. In: Schmidt HAE, Chambion J (eds) Nuclear medicine. Quantitative analysis in imaging and function. Schattauer, Stuttgart, pp 11-13

18. Markwalder TM, Grolimund P, Seiler RW, Roth F, Aaslid R (1984) Dependency of blood flow velocity in the middle cerebral artery on end-tidal carbon dioxide partial pressure-a transcranial ultrasound Doppler study. J Cereb Blood Flow Metab 4:368-372

19. Jansen-Olesen I, Jørgensen L, Engel U, Edvinsson L (2003) Indepth characterization of CGRP receptors in human intracranial arteries. Eur J Pharmacol 481:207-216

20. Friberg L, Olesen J, Iversen HK, Sperling B (1991) Migraine pain associated with middle cerebral artery dilatation: reversal by sumatriptan. Lancet 338:13-17

21. Stanley JC, Martin JL, Barron ME, Lovick AHJ, Nelson RJ, Richards HK, Pickard JD (1990) A study of the cardiovascular and cerebrovascular effects of calcitonin gene-related peptide in human volunteers. J Physiol Nottingham Meeting 427:33

22. Olesen J (1974) Cerebral blood flow. Methods for measurements, regulation, effects of drugs and changes in disease. Acta Neurol Scand 50(Suppl 57):24-25

23. Edvinsson L, Nilson E, Jansen-Olesen I (2007) Inhibitory effect of BIBN4096BS, CGRP $_{8-37}$, a CGRP antibody and an RNASpiegelmer on CGRP induced vasodilation in the perfused and non-perfused rate middle cerebral artery. $\mathrm{Br} \mathrm{J}$ Pharmacol 150:633-640

24. Oliver KR, Wainwright A, Edvinsson L, Pickard JD, Hill RG (2002) Immunohistochemical localization of calcitonin receptorlike receptor and receptor activity-modifying proteins in the human cerebral vasculature. J Cereb Blood Flow Metab 22:620 629

25. Juul R, Aakhus S, Björnstad K, Gisvold SE, Brubakk AO, Edvinsson L (1994) Calcitonin gene-related peptide (human $\alpha$-CGRP) counteracts vasoconstriction in human subarachnoid haemorrhage. Neurosci Lett 170:67-70 